range of parameters. Even in the simple Ricker model, with only one parameter in the fitness function (model 1 in ref. 1), the spectrum changes for different parameter values: increasing the growth rate $r$ flattens the spectrum (Fig. 1, curve $a$ ), and it becomes reminiscent of white noise, where all frequencies have equal power.

More sophisticated models, with more parameters, are more flexible, and the changes can be more dramatic. For example, in the Maynard Smith model $f\left(P_{t}\right)=$ $r \cdot\left[1+\left(a P_{t}\right)^{b}\right]^{-1}$ (model 5 in ref. 1), the dynamics are determined by the parameter $b$, describing the type and strength of competition, and by the intrinsic growth rate $r$, whereas $a$ scales the carrying capacity. In this model, large values of $b$ (severe density dependence) and small values of $r$ typically yield reddened spectra with more power at low frequencies (Fig. 1, curve $b$ ).

A very general model for density dependence, not analysed by Cohen ${ }^{1}$, is Bellows' $^{4}$ fitness function $f\left(P_{t}\right)=$ $r \cdot \exp \left[-\left(a P_{t}\right)^{b}\right]$. (The Maynard Smith model is a simplified version obtained by truncating a Taylor series expansion of the denominator.) In this model, reddened power spectra (Fig. 1, curve $c$ ) are common. An index for the colour of a spectrum is the ratio between the area under the spectrum ranging from 0 to 0.25 and

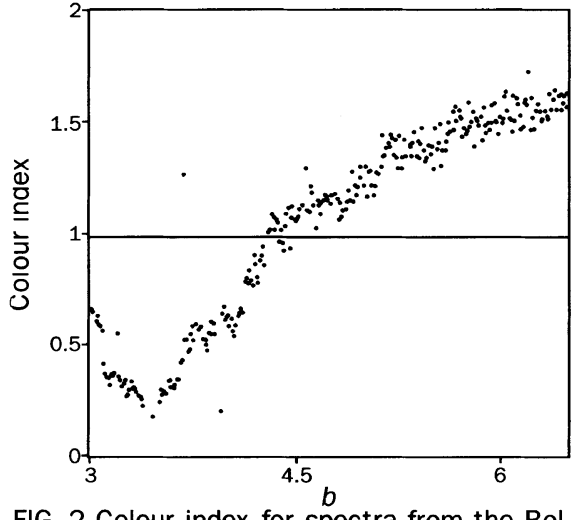

FIG. 2 Colour index for spectra from the Bellows model (see text). White noise has an index of 1 (horizontal line). Indices larger than 1 indicate reddened spectra and those smaller than 1 blue spectra. Outliers in the figure correspond to spectra with discrete peaks in the sense of Cohen ${ }^{1}$.

the area ranging from 0.25 to 0.5 : the ratios of blue spectra with more power at high frequencies are smaller than 1 , while those of red spectra are larger than 1.

Figure 2 shows the colour index for the spectra corresponding to 300 values of parameter $b$ in the interval $[3,6.5]$. The other parameters were fixed at $r=2.5$ and $a=0.005$. Only $b$ values leading to chaotic time series were considered. The lower

\title{
Why squid can breathe easy
}

SIR - Cephalopods are all predators and typically have high metabolic rates. Nevertheless, a huge biomass of squid apparently live in the deep oceans, often in severely hypoxic waters ${ }^{1}$. This prompted us to examine the gills of various deepsea cephalopods. Compared with their shallow-water relatives, squid from the cold deep oceans tend to have large gill areas and very thin blood-water barrier thicknesses ${ }^{2}$ (see table). Among fish, only the warm-blooded tuna ${ }^{3,4}$ have similar weight-specific gill areas and comparable barrier thicknesses. The limited data available on the morphometrics of deepwater fish gills suggest that these gill areas are actually reduced in comparison with shallow-water species ${ }^{5}$.

Estimates of the gill diffusion capacities of deep-water squid indicate that these animals could remain active, swimming about rapidly even in the oxygenminimal layers of the open ocean. The price is very fragile gills. Cephalopods can tolerate these conditions where fish cannot because the gills do not form part of the buccal apparatus; there is no danger of damage from sharp fragments of cuticle, scales and bones penetrating the gills when the animal feeds. Deep-water squid are living in an environment where only very clear, grit-free water enters the mantle - even the anus is downstream of the gills. We suspect that very high oxygen limit of the $b$ interval was chosen to ensure that chaotic time series are possible, the upper limit to prevent unrealistically large fluctuations in these trajectories. Red spectra occur for a broad range of $b$ values describing intermediate to strong competition.

We conclude from our calculations that blue spectra are indeed easy to observe in the models considered by Cohen. For each model, however, there is a range of parameters where fluctuations are chaotic but the corresponding spectra are reddened, or at least very similar to white noise. For the equations of Bellows and Maynard Smith, which are the most general one-dimensional ecological models ${ }^{4,5}$, reddened spectra are common, especially when competition is intense. The open question posed by these results and by Cohen's is to understand when and why some parameter values give blue spectra and others red spectra.

\section{Albert Blarer}

\section{Michael Doebeli}

Zoology Institute, University of Basel,

Rheinsprung 9,

\section{CH-4051 Basel, Switzerland}

1. Cohen, J. E. Nature 378, 610-612 (1995)

2. Sugihara, G. Nature $378,559-560$ (1995)

3. Halley, J. M. Trends Ecol. Evol. 11, 33-37 (1996)

4. Bellows, T. S. Jr J anim. Ecol 50, 139-156 (1981).

5. Doebeli, M. Theor. Populat. Biol. 47, 82-106 (1995).

diffusion capacities of these fragile gills give squid like Bathyteuthis or Brachioteuthis a much-needed edge in their competition with fish and are perhaps in part responsible for the huge numbers of cephalopods to be found in the deep oceans.

\section{J. J. Madan}

\section{J. Wells}

Department of Zoology,

University of Cambridge,

Cambridge CB2 3EJ, UK

1. Clarke, M. R. in Cephalopod Life Cycles Vol. 2 (ed. Boyle, P. R.) 221-237 (Academic, London, 1987). Madan, J. J. thesis (Univ. Cambridge, 1995).

2. Madan, J. J. thesis (Univ. Cambridge, 1995).
3. Perry, S. F. in Oxygen Transport in Biological Systems (eds Eggington, S. \& Ross, H. F.) 57-77 (Cambridge Univ. Press, 1992)

4. Hughes, G. M. Respir. Physiol. 14, 1-25 (1972)

5. Hughes, G. M. J. Linn. Soc. Zool. 59, 195-208 (1976)

6. Eno, N. C. J. Mar. Biol. ass. U.K. 74, 687-706 (1994).

\begin{tabular}{|c|c|c|c|c|c|}
\hline \multicolumn{6}{|c|}{ CEPHALOPOD GILL DATA } \\
\hline Cephalopod species & Weight & $\begin{array}{l}\text { Ambient seawater } \\
\text { oxygen content }\end{array}$ & Gill area & $\begin{array}{l}\text { Blood-water } \\
\text { diffusion barrier }\end{array}$ & Gill diffusion capacity \\
\hline Deep-water species & (g) & $(\mathrm{ml}$ per I) & $\left(\mathrm{cm}^{2}\right.$ per $\left.\mathrm{g}\right)$ & $(\mu \mathrm{m})$ & $\begin{array}{c}\left(\mathrm{ml} \mathrm{O}_{2} \text { per kg per } \mathrm{mmHg}\right. \\
\text { per min) }\end{array}$ \\
\hline Bathyteuthis abyssicola $^{2}$ & 4.27 & 2.59 & 21.88 & 1.10 & 2.999 \\
\hline${\text { Brachioteuthis } \text { riisei }^{2}}^{2}$ & 8.26 & 3.23 & 45.14 & 1.01 & 3.160 \\
\hline Cranchia scabra $^{2}$ & 11.51 & 3.73 & 27.04 & 3.10 & 0.755 \\
\hline Liocranchia reinhardti $^{2}$ & 5.49 & 2.59 & 13.33 & 1.58 & 0.882 \\
\hline Histioteuthis reversa ${ }^{2}$ & 37.09 & 4.44 & 11.87 & 2.52 & 0.435 \\
\hline Octopoteuthis danae ${ }^{2}$ & 26.53 & 3.43 & 8.96 & 1.63 & 0.492 \\
\hline Vampyroteuthis infernalis ${ }^{2}$ & 18.81 & 3.62 & 4.74 & 3.34 & 0.311 \\
\hline \multicolumn{6}{|l|}{ Shallow-water species } \\
\hline Octopus vulgaris ${ }^{6}$ & 40.00 & 5.15 & 5.40 & 8.58 & 0.058 \\
\hline Eledone moschata ${ }^{2}$ & 334.00 & 5.15 & 2.91 & 14.98 & 0.025 \\
\hline Alloteuthis subulata ${ }^{6}$ & 8.98 & 5.15 & 11.76 & 6.19 & 0.274 \\
\hline Lolliguncula brevis $^{2}$ & 10.58 & 5.15 & 7.03 & 1.34 & 0.512 \\
\hline
\end{tabular}

